\title{
The Effect of Morphology on the Biodegradation Behavior of Porous Magnesium Bone Scaffold
}

\author{
Hasan Basri 1,", Ardiansyah Syahrom ${ }^{2,3}$, Amir Putra Md Saad ${ }^{2,3}$, Rabiatul Adibah $\mathrm{AR}^{2,3}$, \\ Akbar Teguh Prakoso ${ }^{1}$, Apreka Diansyah ${ }^{1}$, and Risky Utama Putra ${ }^{1}$ \\ ${ }^{1}$ Department of Mechanical Engineering, Faculty of Engineering, Universitas Sriwijaya, 30622 \\ Inderalaya, Kabupaten Ogan Ilir, Indonesia \\ ${ }^{2}$ Department of Applied Mechanics and Design, Faculty of Mechanical Engineering, Universiti \\ Teknologi Malaysia, 81310 Sekudai, Johor, Malaysia \\ ${ }^{3}$ Sports Innovation and Technology Centre (SITC), Institute of Human-Centered and Engineering \\ (IHCE), Universiti Teknologi Malaysia, 81310 Sekudai, Johor, Malaysia
}

\begin{abstract}
The purpose of this study is to analyze the influence of morphology on the degrading behavior of porous magnesium bone scaffold by using computer simulation. Based on the experimental work, the three bone scaffold prepared with $30 \%, 41 \%$, and $55 \%$ of porosity, respectively. The bone scaffold made of pure magnesium that immersed in simulated body fluid (SBF) for 72 hours with constant flow rates of $0.025 \mathrm{ml} / \mathrm{min}$. After degradation, each specimen was scanned by $\mu \mathrm{CT}$ with a resolution of $17 \mu \mathrm{m}$. In this study, three different morphology before and after degradation was performed by computer simulation using the FSI method. Each specimen before and after degradation were given different bone strain (1000-3500 $\mu$ strain) that create displacement variations on the bone scaffold. Before degradation, the outcomes showed that the variation of displacement affects fluid characteristic change and for the specimen $\mathrm{C}$ ( $55 \%$ of porosity) generates the highest permeability with the value of 8.78 x $10^{-10} \mathrm{~m}^{2}$. After degradation, specimen A ( $30 \%$ of porosity) has a higher average shear stress of $2.04 \times 10^{-3} \mathrm{~Pa}$, specimen $\mathrm{C}$ (55\% of porosity) has degradation rate of $3.37 \mathrm{mg} / \mathrm{cm}^{2} / \mathrm{d}$ and the highest porosity of $75.81 \%$.
\end{abstract}

\section{Introduction}

Osteoporosis, injury, and trauma to the bone can cause damage and degeneration of bone tissue in the human body, requiring treatment to facilitate tissue repair including replacement or regeneration. The alternative solution in the healing of bone problems is the development of tissue engineering. The main role in the tissue engineering, repair and replace cells that have been damaged or degenerated to restore functional microstructure and mechanical properties of the tissue to its original state. The tissue engineering is currently generally used porous scaffolds to allow nutrients to pass through bone scaffold for tissue regeneration [1]. In order to be successfully applied in a healthy human body, the

*Corresponding author: hasan_basri@unsri.ac.id 
bone scaffold must have morphology, micro-architecture, mechanics, and biodegradation behavior to be compatible with the bone tissue. The porosity of bone scaffolds has to show $25 \%-90 \%$ porosity and the pore size of $10-1000 \mu \mathrm{m}$ to provide essential nutrients and oxygen to cell survivability [2]. Magnesium $(\mathrm{Mg})$ is a promising biodegradable metal for bone implants due to its mechanical properties are close to the human bone and its potential to degrade without causing a toxicological problem [3]. The biodegradation behavior of biodegradable metals should be investigated thoroughly when applied in the body due to it should have to be degraded along with the formation of new bone tissue in order not to need surgery for the second time [4]. The morphology of bone scaffolds affects the transport system of oxygen and biological fluid for their maintenance and survivability [5]. Human bones support different physiological loads, depending on the activities carried out by humans themselves. With variations in mechanical loading provided by the human physiological burden itself, these variations produce varying strains on the bones. Usually, in the range of $1000-3500 \mu \varepsilon$, where $1000 \mu \varepsilon$ when the human body relaxes, $2000 \mu$ when walking, and $3500 \mu$ when the heaviest loading is carried out by the human body such as running $[3,6]$.

The degradation behavior of the bone scaffold includes permeability and wall shear stress (WSS) is a significant thing to investigate because of making an effect on cell bioactivity directly in bone scaffolds $[7,8]$. A permeable bone scaffold must have the ability to pass nutrients, gases and waste emissions effectively through its channels for maintenance and survivability [9]. Many studies have been performed to find out the factors that influence the permeability and WSS. O'Brien et al. [1] conducted experimental and mathematical analysis, they found that porosity affected the permeability of bone scaffold [10] Another study by an experimental and computational analysis probed that the increasing porosity and pore size will improve the permeability of the bone scaffold [11]. [12] have been conducted computational fluid dynamics analysis to find out the influence of shape (geometrical parameters) on WSS and pore size. Their findings indicate that mechanical stimuli in bone scaffolds significantly affect pore size compared to porosity and structural architecture.

In addition, to the development of a bone scaffold, many factors to be considered such as fluid transport phenomena, geometry, and mechanical properties [12,13]. Based on some published report, commonly the experimental study focuses on transport phenomena of fluid [14-18]. The previous study by Md Saad [21] has been conducted experimental work to investigate the in vitro degradation of porous magnesium of the bone scaffold in dynamic immersion test under different flow rates. The results showed that different flow rates cause the significant degradation behavior and the mechanical integrity to decrease on the bone scaffold. In this study performed a computational simulation based on FSI to determine the effects of the different morphology of scaffold architecture on the biodegradation behavior of porous magnesium bone scaffold. The flow rate that using in this simulation was 0.025 $\mathrm{ml} / \mathrm{min}$.

\section{Materials and Methods}

\subsection{Preparation of 3D model of Bone Scaffold}

The morphology of the 3D model before degradation with variations of models $\mathrm{A}, \mathrm{B}$, and $\mathrm{C}$ was taken based on the previous study by Md Saad [21]. Respectively, the percentage of porosity of the three models A, B, and C were $30 \%, 41 \%$, and $55 \%$ as shown in Table 1. The 3D model before degradation was generated using SolidWorks 2014 software which is a cuboid shape with measuring $5 \times 5 \times 3 \mathrm{~mm}$ and the pore size is $0.8 \mathrm{~mm}$ 
as shown in Figure 1. For the 3D model after degradation was taken based on the previous study by [20] based on a 72 hour immersion period with variations of models A, B, and C which can be seen in Figure 2.

Table 1. The morphological details of the bone scaffold [21].

\begin{tabular}{|c|c|c|c|c|c|c|}
\hline Type & $\begin{array}{c}\text { Porosity } \\
\text { (\%) }\end{array}$ & $\begin{array}{l}\text { Mass } \\
(\mathrm{mg})\end{array}$ & $\begin{array}{l}\text { Surface area } \\
\quad\left(\mathrm{mm}^{2}\right)\end{array}$ & $\begin{array}{c}\text { Volume } \\
\left(\mathrm{mm}^{3}\right)\end{array}$ & $\begin{array}{c}\text { Mass per } \\
\text { surface area } \\
\left(\mathrm{kg} / \mathrm{m}^{2}\right)\end{array}$ & $\begin{array}{c}\text { Surface area per } \\
\text { volume }\left(\mathrm{m}^{-1}\right)\end{array}$ \\
\hline A & 30 & 82.8 & 189.30 & 52.87 & 0.44 & 3580.48 \\
\hline B & 41 & 70.3 & 209.81 & 44.57 & 0.34 & 4707.43 \\
\hline $\mathrm{C}$ & 55 & 53.3 & 225.75 & 33.83 & 0.24 & 6673.07 \\
\hline
\end{tabular}

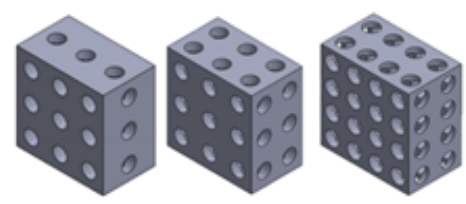

Fig. 1. Snapshots of CAD models of bone scaffold before degradation
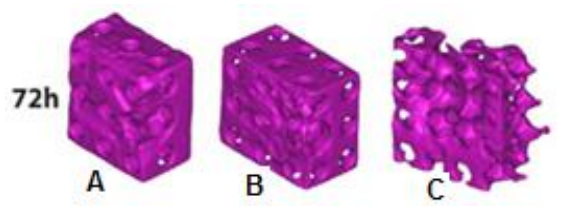

Fig. 2. The 3D model after degradation with 72 hours of immersion time [20]

\subsection{Simulation Procedure}

In this study, the Comsol Multiphysics 4.4 software was used to perform computer simulation. The boundary condition was based on the previous study by Md Saad [21] as shown in Fig 3. The tetrahedral elements were utilized in this simulation and properties of the SBF fluid was incompressible fluid, $1000 \mathrm{~kg} / \mathrm{m}^{3}$ of density and $0.001 \mathrm{~Pa}$.s of dynamic viscosity.

\subsection{Permeability Determination}

The permeability of the bone scaffold calculated by Darcy's law using Equation (1).

$$
\mathrm{Q}=\left(\frac{\mathrm{kA}}{\mu}\right)\left(\frac{\Delta \mathrm{P}}{\mathrm{L}}\right)
$$

Where, $\mathrm{Q}$ is the flow rate $\left(\mathrm{m}^{3} / \mathrm{s}\right), \mathrm{A}$ is the surface area $\left(\mathrm{m}^{2}\right), \mu$ is the dynamic fluid viscosity (Pa.s), $\Delta \mathrm{P}$ is the pressure drop $(\mathrm{Pa}), \mathrm{L}$ is the length of the specimen $(\mathrm{m})$ and $\mathrm{k}$ is the permeability $\left(\mathrm{m}^{2}\right)$. For each simulation, pressure data i.e inlet pressure and the outlet pressure are drawn on the modeling of the fluid passing through the bone scaffold, precisely $1.5 \mathrm{~cm}$ at the inlet and outlet points from the center point of the bone scaffold.

\subsection{Mesh Sensitivity Study}

In this work, the sensitivity analysis of mesh simulation with FSI method uses Von Misses stress parameters. The number of elements between 150.000-300.000 used as a 
meshing value because it is more effective in simulation and the percentage of errors that can still be tolerated. The simulation procedure in this study requires about 5 hours. The convergence study in this simulation is shown in Figure 4.

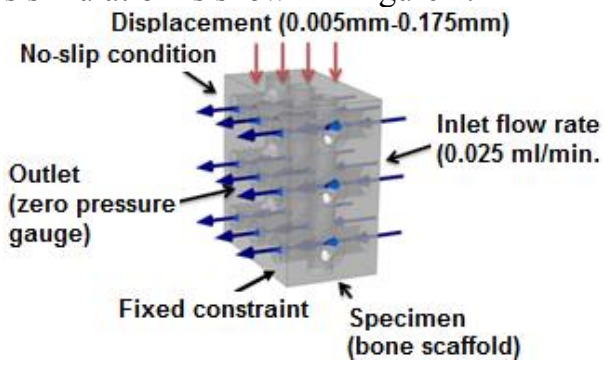

Fig. 3. The boundary conditions used in FSI simulation.

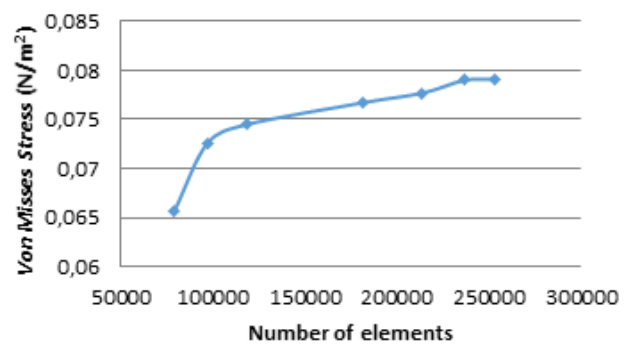

Fig. 4. Convergence study analysis.

\section{Results and Discussions}

The simulation was executed with a flow rate of $0.025 \mathrm{ml} /$ minute using the FSI method. Simulations include three samples before degradation and three samples after degradation. Variation of displacement on the bone scaffold occurs due to human physiological activities were $0.005 \mathrm{~mm}, 0.01 \mathrm{~mm}$, and $0.0175 \mathrm{~mm}$. The results of 3D bone scaffold simulation using the FSI method are wall shear stress and fluid pressure. Data from the simulation results are processed to obtain the permeability, volume, surface area and porosity in the bone scaffold. The simulation results will be displayed through graphics and $2 \mathrm{D}$ visuals.

\subsection{Shear stresses on samples before and after degradation}

The shear rate contour plot of the samples before degradation and samples after degradation of 72 hours immersion time under a flow rate of $0.025 \mathrm{ml} / \mathrm{min}$ at different displacement are shown in Figure 5 and Figure 6.
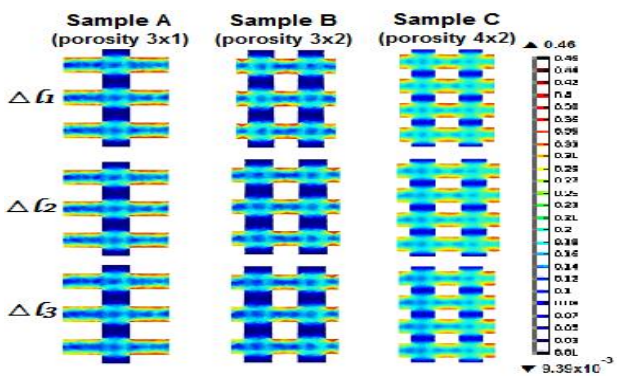
Fig. 5. Shear stress contours of samples before degradation.

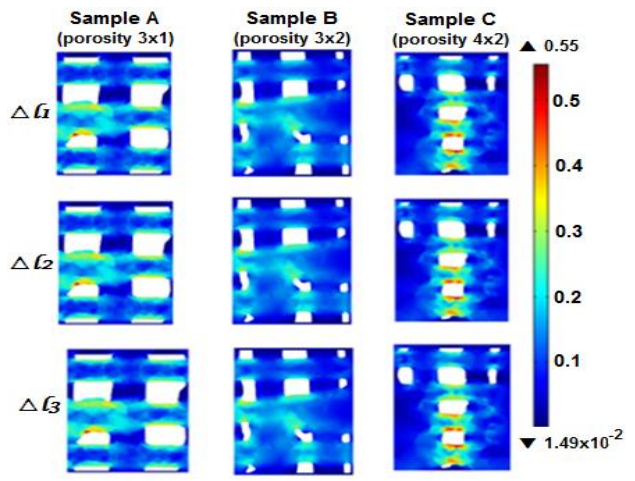

Fig. 6. Shear stress contours of samples after degradation at 72 hours of immersion time.

The contour plot took off the middle of the porous samples. Based on the contour, the shear stress that occurs on the exposed surface, precisely localized in the middle of the porous bone scaffold. Based on Figure 5, contour shear stress was affected by different displacement and different morphology of samples A, B, and C. Samples B had a higher average shear stress compared samples A and C as shown in Figure 7. Based on Figure 6, contour shear stress was not affected by different displacement because contour was shown at the same level of color. But, based on the different samples of morphology, the shear stress contour showed a different level of color. Specimen A had a higher average shear stress compared to samples $\mathrm{B}$ and $\mathrm{C}$ as shown in Figure 7. In the simulation results carried out for samples after degradation, displacement does not involve changes in shear stress. Elements that influence these things are because of the differences in the naming of the plate domain as a representation of the essence due to physiological activity. In the sample before degrading, the load given uses a plate with 3 loads, but the sample after degradation was not given a plate during the meshing process because the surface of the sample after degradation was complicated so it failed in the meshing process.

The bone marrow is the fluid that brings nutrients and oxygen when it is through cancellous bone. The bone marrow that moves past the bone scaffold causes shear stress on the bone scaffold and also degrades the bone scaffold. Many studies have been conducted to investigate and asses the degrading behavior of porous magnesium such as dynamic immersion test by [21]. The computer simulation using CFD analysis also conducted by al. [20] to investigate shear stress on the bone scaffold.

Based on FSI analysis, the maximum average shear stress of the bone scaffold before degradation under the flow rate of $0.025 \mathrm{ml} / \mathrm{min}$ was $1.10 \times 10^{-3}-1.98 \times 10^{-3} \mathrm{~Pa}$, as shown in Figure 7. The different shear stresses occur in the exposed surface area of the bone scaffold due to the different morphology of the bone scaffold. The cross-section with a higher exposed surface area generated lower shear stress compared to the low exposed surface area. From the previous work conducted by[20,21], the shear stress obtained was $0.12 \times 10^{-5} \mathrm{~Pa}-5.74 \times 10^{-5} \mathrm{~Pa}$. In this study, the value of shear stress obtained is higher than the value of the shear stress of the previous study, this can occur due to different boundary conditions and method of analysis. [20,21] conducted the simulation in their study using CFD method and the boundary condition of the bone scaffold was not integrated with the bone strain. 


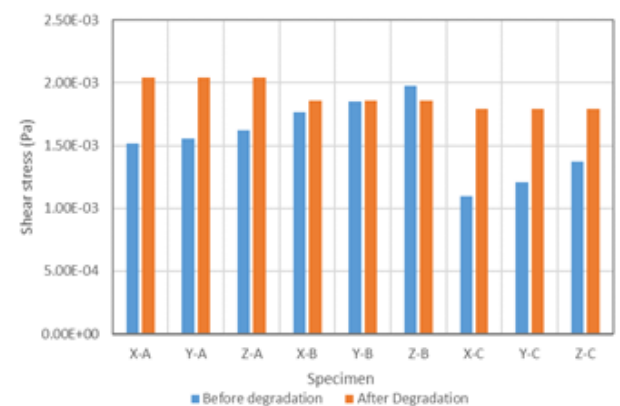

Fig. 7. Shear stress of the samples before and after degradation at different morphology and displacement of flow rate $0.025 \mathrm{ml} / \mathrm{min}$ (Note: $\mathrm{X}, \mathrm{Y}$, and $\mathrm{Z}$ refers to the displacement of $0.005 \mathrm{~mm}$, $0.01 \mathrm{~mm}$, and $0.175 \mathrm{~mm}$ ).

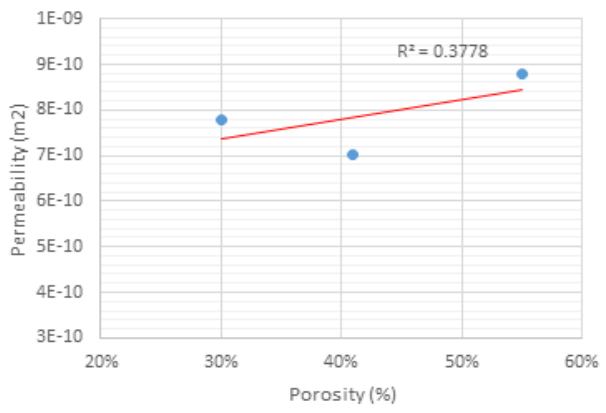

Fig. 8. The relationship between permeability and porosity of the bone scaffold before degradation.

\subsection{Relationship between permeability and porosity of the bone scaffold}

The permeability of the bone scaffold was found to depend on the surface area and porosity [10]. Figure 8 shows the permeability of the specimen before degradation. The permeability of porous magnesium specimen increases as the porosity increases. The significance level of the correlation was $37.78 \%$.

Porous of bone scaffold has the function to best nutrients passing through it to speed up tissue regeneration. The bone scaffold with high permeability will be better in the regeneration process [7]. In this present study, the permeability was lower than the previous work of [20]. Figure 8 showed that specimen $\mathrm{C}$ (55\% of porosity) was the highest permeability compare to the specimen A ( $30 \%$ of porosity) and B ( $41 \%$ of porosity).

Figure 9 shows the comparison between cancellous bone permeability from previous experimental and simulation studies and permeability of bone scaffolds in the present study. Based on several experiments that have been conducted before, cancellous bone permeability ranges from $2.56 \times 10^{-11} \mathrm{~m}^{2}$ to $7.43 \times 10^{-8} \mathrm{~m}^{2}$. The cancellous bone samples were taken from the vertebral body of the calcaneus [15], the femoral bone [11,23], and the lumbar vertebrae [9]. Based on several computational simulation studies on the cancellous bone, there has been reported that the range value of permeability was $1.4 \times 10^{-7} \mathrm{~m}^{2}$ to $2.8 \times$ $10^{-7} \mathrm{~m}^{2}$ [22]. Based on the previous work by [20], the range permeability was $2.2 \times 10^{-7}$ to $3.94 \times 10^{-7} \mathrm{~m}^{2}$ [20]. In this present study, the value of permeability ranging from $7.8 \times 10^{-10}$ $\mathrm{m}^{2}$ to $8.8 \times 10^{-10} \mathrm{~m}^{2}$. The result shows good agreement with bulk cancellous bone on computational simulation in the previous study by [16]. 


\subsection{Relationship Between Porosity of Bone Scaffold and Time Degradation}

Figure 10 shows the relationship of porosity with time degradation. In the figure shows the increasing time degradation will increase the porosity of the bone scaffold. For each of sample $\mathrm{A}, \mathrm{B}$, and $\mathrm{C}$, the relationship between porosity and degradation time shows the correlation value of $\mathrm{R}^{2}$ that is 1 . This indicated that the relationship of porosity with the time of degradation has a very strong correlation.

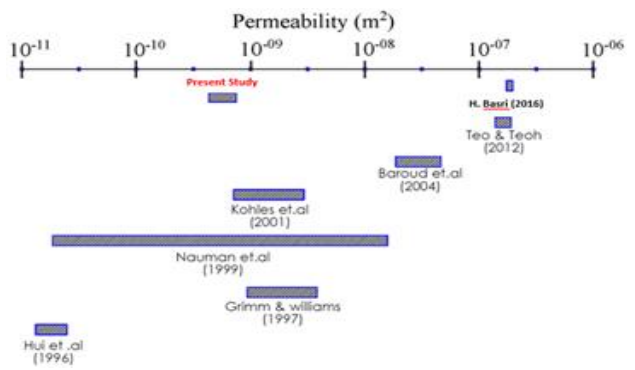

Fig. 9. Comparison between permeability values of cancellous bone from previous experimental and simulation studies and permeability of bone scaffold in the present study.

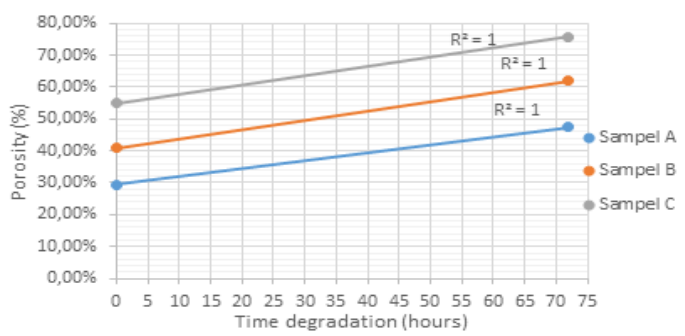

Fig. 10. The relationship between porosity of the bone scaffold and time degradation.

\subsection{Relationship Between Degradation Rate and the Specimens Of Bone Scaffold}

The initial design of the porosity of each specimen (A, B, and C) was 30\%, 41\%, $55 \%$, respectively. Figure 11 shows the degradation rate of the specimen at 72 hours of immersion time. The figure shows that specimen $\mathrm{C}$ was the highest degradation rate compared to specimen $\mathrm{A}$ and $\mathrm{B}$. The initial design of porosity affects the degradation rate of the bone scaffold. It was found that the bone scaffold with the highest initial design of porosity (specimen C) will generate the highest degradation rate.

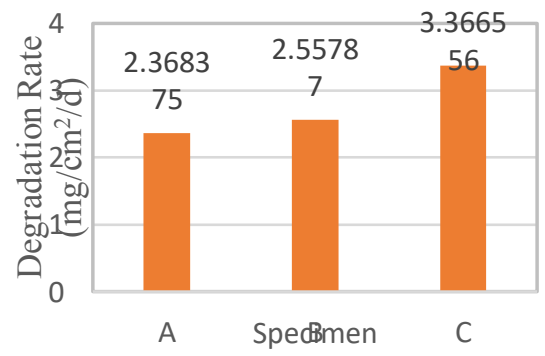

Fig. 11. The degradation rate of the bone scaffold at 72 hour immersion time. 


\section{Conclusions}

From the results and discussions above, it can be concluded as follows:1) a specimen with a cross-section of higher exposed surface area generates lower shear stress compared to the low exposed surface area. After degradation, specimen A (30\% of porosity) has a higher average shear stress of $2.04 \times 10^{-3} \mathrm{~Pa} .2$ ) specimen $\mathrm{C}(55 \%$ of porosity) generates the highest permeability of $8.78 \times 10^{-10} \mathrm{~m}^{2}$ and degradation rates of $3.37 \mathrm{mg} / \mathrm{cm}^{2} / \mathrm{d}$ and 3 )the increase of time degradation generates the higher porosity on the bone scaffold. Specimen $\mathrm{C}$ with 72 hours of immersion time has the highest porosity of $75.81 \%$.

\section{Acknowledgments}

This study was part of an International Research Collaboration between Universitas Sriwijaya, Indonesia and the Universiti Teknologi Malaysia, Malaysia.

\section{References}

1. F.J. O’Brien. J. Mater. Today 14, 3 (2011)

2. L. Polo-Corrales, M. Latorre-Esteves, J.E. Ramirez-Vick, J. Nanosci. Nanotechnol 14, 1, (2014)

3. F. Witte, A.Eliezer. J. Degrad. Implant Mater 9781461439 (2012)

4. J. Wang, C. E. Smith, J. Sankar, Y. Yun, N. Huang. J. Regen. Biomater 2, 1 (2015)

5. L. Savarino et al., J. Biomaterials 28, 20 (2007)

6. F. Witte et al., J. Materwiss. Werksttech 37, 6 (2006)

7. A. G. Mitsak, J. M. Kemppainen, M. T. Harris, S. J. Hollister. J. Tissue Eng. Part A, 17 (2011)

8. M. Bartnikowski, T. J. Klein, F. P. W. Melchels, M. A. Woodruff. J. Bioeng 111, 7 (2014)

9. V. Serpooshan et al., J. Acta Biomater 6, 10 (2010).

10. F. J. O'Brien, B. A. Harley, M. A. Waller, I. V Yannas, L. J. Gibson, P. J. Prendergast. J. Technol. Heal. Care 15, 1 (2007).

11. M. R. Dias, P. R. Fernandes, J. M. Guedes, S. J. Hollister. J. Biomech 45, 6 (2012)

12. F. Zhao, T. J. Vaughan, L. M. McNamara. J. Biomech. Model. Mechanobiol. 15, 3 (2016)

13. S. Majumdar et al., J. Bone 22, 5 (1998)

14. T. S. Kaneko, J. S. Bell, M. R. Pejcic, J. Tehranzadeh, and J. H. Keyak. J .Biomech. 37, 4 (2004).

15. R. S. Ochia, R. P. Ching. J. Biomech. Eng 124, 5 (2002)

16. E. A. Nauman, K. E. Fong, and T. M. Keaveny. J. Ann. Biomed. Eng 27, 4 (1999)

17. G. Baroud, J. Z. Wu, M. Bohner, S. Sponagel, T. Steffen. J. Med. Eng. Phys 25, 4 (2003)

18. M. J. Grimm, J. L. Williams, J. Biomech 30, 7 (1997)

19. S. S. Kohles, J. B. Roberts, M. L. Upton, C. G. Wilson, L. J. Bonassar, A. L. Schlichting. J. Biomech 34, 9 (2001)

20. H. Basriet al., Malaysian Journal of Fundamentals and Applied Sciences (2017)

21. A. P. Md Saad et al., J. Mater. Des 122 (2017) 
22. A. Syahrom, M. R. Abdul Kadir, J. Abdullah, and A. Öchsner. J. Med. Eng. Phys 35, $6(2013)$ 